\title{
The role of sphingolipid signalling in diabetes-associated pathologies (Review)
}

\author{
MEI LI NG ${ }^{1-3}$, CAROL WADHAM $^{4}$ and OLGA A. SUKOCHEVA ${ }^{5}$ \\ ${ }^{1}$ Centenary Institute of Cancer Medicine and Cell Biology, Sydney, NSW 2050; ${ }^{2}$ Sydney Medical School, \\ Faculty of Medicine, University of Sydney, Sydney, NSW 2006, Australia; ${ }^{3}$ Advanced Medical and Dental Institute, \\ University Sains Malaysia, Kepala Batas, Penang 13200, Malaysia; ${ }^{4}$ Children's Cancer Institute Australia, \\ Lowy Cancer Research Centre, University of New South Wales, Randwick, NSW 2031; \\ ${ }^{5}$ School of Social Health Sciences, Flinders University, Bedford Park, SA 5042, Australia
}

Received June 29, 2016; Accepted November 14, 2016

DOI: $10.3892 / \mathrm{ijmm} .2017 .2855$

\begin{abstract}
Sphingosine kinase (SphK) is an important signalling enzyme that catalyses the phosphorylation of sphingosine ( $\mathrm{Sph}$ ) to form sphingosine-1-phosphate (S1P). The multifunctional lipid, S1P binds to a family of five $\mathrm{G}$ protein-coupled receptors (GPCRs). As an intracellular second messenger, S1P activates key signalling cascades responsible for the maintenance of sphingolipid metabolism, and has been implicated in the progression of cancer, and the development of other inflammatory and metabolic diseases. SphK and S1P are critical molecules involved in the regulation of various cellular metabolic processes, such as cell proliferation, survival, apoptosis, adhesion and migration. There is strong evidence supporting the critical roles of SphK and S1P in the progression of diabetes mellitus, including insulin sensitivity and insulin secretion, pancreatic $\beta$-cell apoptosis, and the development of diabetic inflammatory state. In this review, we summarise the current state of knowledge for SphK/S1P signalling effects, associated with the development of insulin resistance, pancreatic $\beta$-cell death and the vascular complications of diabetes mellitus.
\end{abstract}

\section{Contents}

1. Introduction

2. Divergence of SphK isoforms

3. Mechanisms of SphK activation and subcellular localization

4. Dual mechanisms of S1P signalling: extracellular and intracellular effects

Correspondence to: Dr Mei Li Ng, Advanced Medical and Dental Institute, University Sains Malaysia, No. 1-8 (Lot 8), Persiaran Seksyen 4, 1, Bandar Putra Bertam, Kepala Batas, Penang 13200, Malaysia

E-mail:nmeili@usm.my

Key words: sphingosine kinase, sphingosine-1-phosphate, insulin signalling, insulin resistance, inflammation, diabetes mellitus
5. The role of SphK/S1P signalling in the development of diabetes and related pathologies

6. The role of SphKs in the progression of diabetes-related complications

7. Summary

\section{Introduction}

Diabetes mellitus is one of the most prevalent metabolic diseases, affecting 347 million individuals worldwide (1). This heterogeneous disease ultimately arises from either the failure of pancreatic $\beta$ cells to produce insulin, and/or the development of insulin resistance in peripheral tissues (2). Type 1 diabetes (T1D; juvenile-onset, approximately $10 \%$ of all patients with diabetes) is often caused by an autoimmune attack on pancreatic $\beta$ cells, resulting in the loss of insulin secretion. T1D represents the insulin-dependent form of diabetes, requiring daily insulin therapy. Type 2 diabetes (T2D; adult-onset, $90 \%$ of all patients with diabetes) is caused by insulin resistance, associated with relative hyperinsulinemia. T2D is usually a non-insulin-dependent form of diabetes. Nevertheless, it requires active and often complex therapeutic interventions. Obesity and associated inflammation are common risk factors for T2D $(3,4)$. Aberrant lipid metabolism and signalling are tightly interconnected with the pathogenesis of obesity, inflammation and diabetes. In this review, we highlight the mechanisms through which the key signalling sphingolipid molecule, sphingosine-1-phosphate (S1P), and S1P-producing enzyme sphingosine kinase (SphK) have been shown to affect diabetes-related pathologies.

There are two major isoforms of SphK (SphK1 and SphK2), each having diverse and compensatory biological functions (Figs. 1 and 2) (5). Both SphKs can phosphorylate sphingosine (Sph) to form S1P, thus activating a variety of extracellular and intracellular signalling mechanisms. Controlled by SphKs, the conversion of pro-apoptotic Sph into the pro-survival molecule, S1P, maintains the equilibrium amid opposing cellular functionsm, such as cell growth, proliferation, secretion and migration on the one side; and apoptosis, senescence, autophagy and growth arrest on the other $(6,7)$. This balance, known as the 'sphingolipid rheostat', has been suggested to 


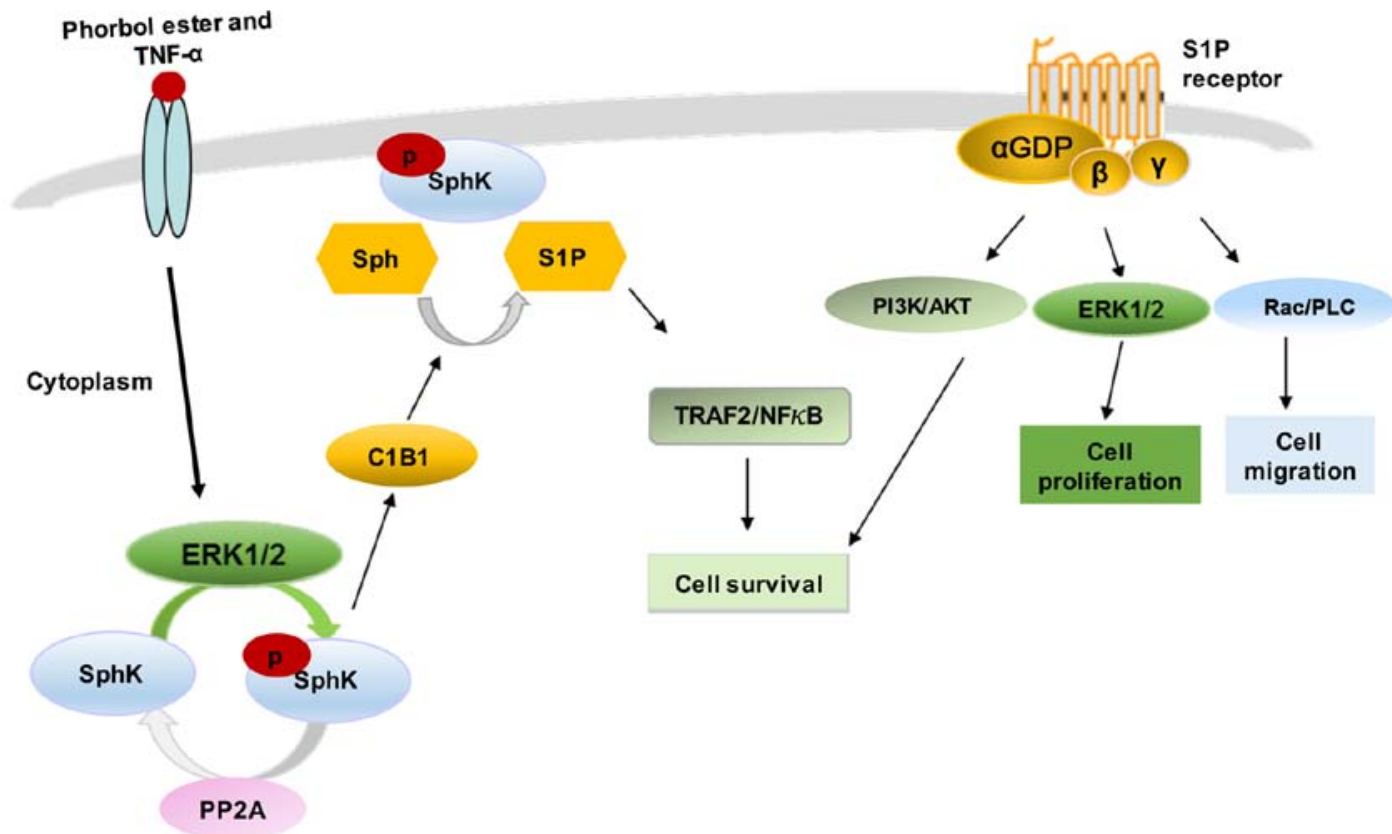

Figure 1. Regulation of SphK1 signalling. SphK1 is located mainly in the cytoplasm. Various agonists (such as phorbol ester and TNF- $\alpha$ ) induce activation of SphK1 phosphorylation, activation and translocation to plasma membrane. This relocation is mediated by interaction with CIB1. S1P is exported from the cells and binds to S1P receptors $\left(\mathrm{S}_{1} \mathrm{P}_{1-5}\right)$ to activate classical GPCR signalling pathways, leading to control of cell survival, proliferation and migration. Alternatively, S1P binds to TRAF2 intracellularly and activates the NF- $\mathrm{BB}$ pathway and its downstream targets. SphK, sphingosine kinase; CIB1, calcium and integrin-binding protein 1; S1P, sphingosine-1-phosphate; GPCR, G protein-coupled receptor; TRAF2, TNF receptor-associated factor 2; NF- $\mathrm{BB}$, nuclear factor $\kappa$-light-chain-enhancer of activated B cells; PLC, phospholipase C; PP2A, protein phosphatase-2A.

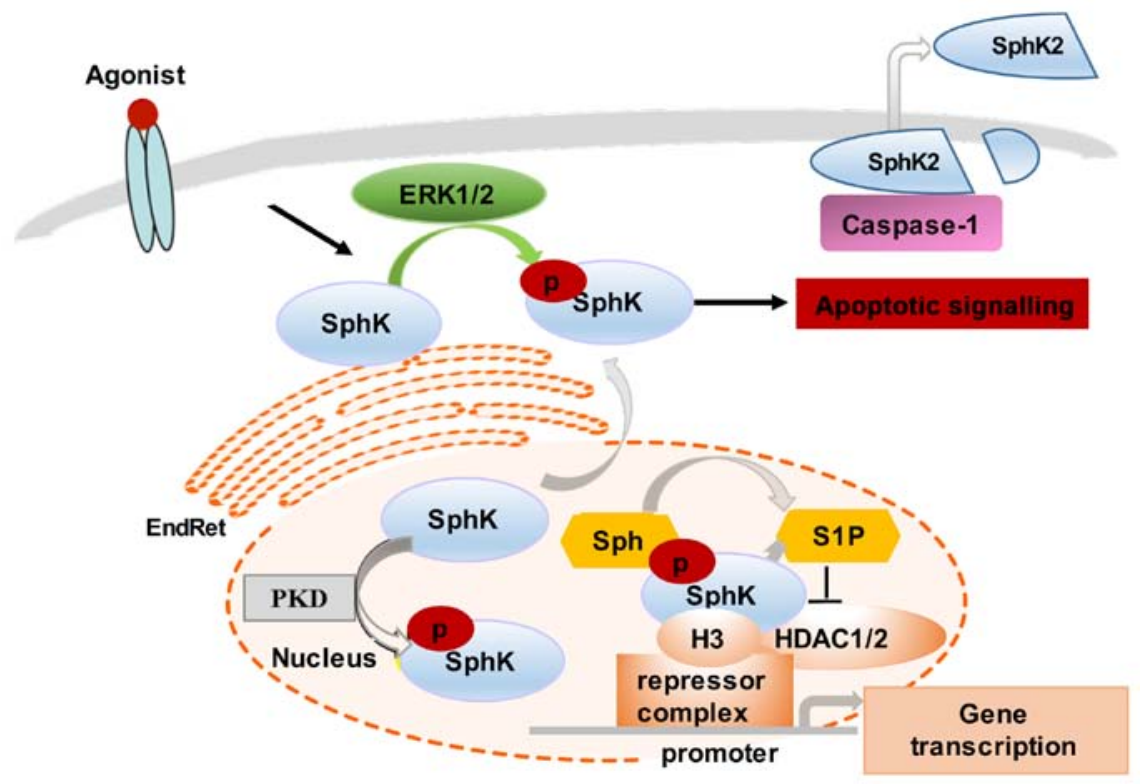

Figure 2. Regulation and SphK2 signalling. Several agonists (such as EGF and cross-linking of FceRI) stimulate SphK2 activation via ERK1/2-mediated phosphorylation. SphK2 in the EndRet induces apoptotic signalling through localised generation of S1P. The release of active SphK2 can also occur via caspase-1-mediated cleavage and allows extracellular generation of S1P. SphK2 localization in the nucleus is regulated via PKD-mediated activation of nuclear export signals. Nuclear SphK2 generates S1P that regulates histone acetylation. S1P specifically binds to the HDAC1/2 and inhibits their enzymatic activity. SphK2 associates with HDAC1/2 in repressor complex at promoters of the genes, where it enhances local $\mathrm{H} 3$ acetylation and promotes gene transcription. SphK, sphingosine kinase; EGF, epidermal growth factor; EndRet, endoplasmic reticulum; S1P, sphingosine-1-phosphate; PKD, protein kinase D; HDAC1/2, histone deacetylase 1 and 2; $\mathrm{H} 3$, histone 3; Sph, sphingosine.

be critical to cell fate $(8,9)$. For example, tipping the balance in favour of Sph accumulation may cause insulin resistance, whereas an increased S1P level has been shown to promote insulin action (10-12).
The highly bioactive lipid, S1P, is involved in maintaining metabolic stability; however, it can also mediate the development of serious pathological conditions (13-15). S1P binds specifically to five $\left(\mathrm{S}_{1} \mathrm{P}_{1-5}\right)$ transmembrane $\mathrm{G}$ protein-coupled 
receptors (GPCRs) (16) and activates cellular responses via S1P receptor-mediated mechanisms and/or by targeting a complex network of intracellular messengers. The biological actions of S1P are cell type- and receptor subtype-specific as reviewed previously (17). In this review, we summarise the recent evidence implicating SphKs/S1P signalling in diabetes-associated intracellular abnormalities and metabolic aberrations.

\section{Divergence of SphK isoforms}

The SphK isoforms (Sphk1 and SphK2) are structurally related, with five highly conserved domains (C1 to $\mathrm{C} 5$ ), although they differ in size, intracellular localization and function. SphK isoforms are encoded by two different genes, SPHK1 (chromosome 17, cytoband q25.1) and SPHK2 (chromosome 19, cytoband q13.33). SphK1 is a $48 \mathrm{kDa}$ protein first purified from rat kidney cells (18). There are three splice isoforms of SphK1 (1a, b and c); all are cytosolic proteins differing slightly in subcellular distribution. SphK2 is larger in size $(69 \mathrm{kDa})$ and has sequence homology to SphK1. There are two recently discovered splice isoforms of SphK2 (a and b) (18). SphK2 contains an extended N-terminal region with a proline-rich polypeptide insertion and several other unique sites within the $\mathrm{N}$-terminal sequence. The $\mathrm{N}$-terminal region of SphK2 includes a nuclear export sequence (NES), important for shuttling the enzyme between the nucleus and cytoplasm. The SphK2 sulphite-binding site facilitates the membrane localization of SphK2 (19), while the caspase-1 cleavage site regulates SphK2 maturation and secretion from cells during the induction of apoptosis (21).

Furthermore, SphK isoforms differ in developmental expression, tissue distribution and subcellular localization $(5,6)$. SphK1 predominates in the lungs and spleen $(7,8,11)$, whereas SphK2 is more common in the heart, brain and liver $(9,10,12,13)$. Notably, SphK1 and SphK2 have been shown to regulate different intracellular processes. For instance, SphK1 promotes cell survival and proliferation, whereas SphK2 is involved in the induction of apoptosis and cell growth arrest (22). The divergent roles of SphK isoforms in diabetes-related pathologies will be discussed in greater detail below.

\section{Mechanisms of SphK activation and subcellular localization}

The different steady-state localization of the SphK isoforms corresponds to the specific intracellular functioning of the enzymes. SphK1/2 are redistributed to distinct intracellular sites in an agonist-dependent manner. SphK1/2 substrates (Sph and dihydrosphingosine) and product (S1P) are lipids and therefore, the subcellular membrane localization of SphK in close proximity to substrates is necessary for the enzyme to fulfill its housekeeping and signalling functions.

SphK localization to specific intracellular compartments is critical to the functional consequences of signalling, such as the stimulation of cancer cell growth (23). Under basal conditions, SphK1 predominates in the cytosol where it maintains low levels of intracellular S1P required for normal cell metabolism (24). It has been documented that the translocation of SphK1 to the plasma membrane is required for its oncogenic effect (23). However, the targeting of SphK1 to a specialised subcellular compartment enables its regulation of different functions. For example, the translocation of SphK1 to the endoplasmic reticulum (EndRet) promotes cell apoptosis (25), whereas the translocation of SphK1 to the nuclear envelope promotes G1/S transition during cell division (22).

Various stimuli, such as growth factors and cytokines can activate SphK1 by phosphorylation of the enzyme at Ser-225, mediated by mitogen-activated protein kinase (MAPK) ERK1/2 (20,21,26,27). This phosphorylation promotes SphK1 to undergo conformational changes accompanied by a rapid increase in the catalytic activity of the enzyme and its subcellular translocation from the cytosol to plasma membrane (26). The continuous retention of SphK1 at the plasma membrane requires binding to phosphatidylserine or phosphatidic acid $(20,21,27)$. In addition to phosphorylation, SphK1 membrane translocation can be also induced by protein-protein interactions (28). SphK1 contains a calmodulin-binding site that binds calcium and integrin-binding protein 1 (CIB1) in a calcium-dependent manner. CIB1 functions as a calcium-myristoyl switch, providing a novel mechanism for SphK1 translocation to the plasma membrane (28).

In comparison to SphK1, SphK2 function-associated localization is less well understood. However, it has been shown that SphK2 can be found both in the nucleus and the cytoplasm, shuttling between these two compartments (28). Similar to SphK1, SphK2 cellular levels and distribution are cell type-specific, agonist-dependent and modifiable by cell culture conditions. For example, SphK2 translocates to the EndRet following serum starvation, which coincides with the induction of apoptosis (29-31). Notably, SphK2 can be released from apoptotic cells by caspase-1-mediated cleavage at its amino terminus (30) (Fig. 2).

Several stimuli, such as epidermal growth factor (EGF) and phorbol ester (PMA) (protein kinase C stimulant) activate SphK2 through MAPK ERK1-mediated phosphorylation at Ser-351 and/or Thr-578 (32). The EGF-induced phosphorylation and activation of SphK2 has been linked to breast cancer cell migration and to the increased invasive capacity of tumor cells (32). The nuclear localization of SphK2 is required for the epigenetic regulation of specific target genes. For instance, SphK2 produces nuclear S1P that binds and, thus, inhibits histone deacetylase 1 and 2 (HDAC1/2) activity, preventing the deacetylation of histone 3. Nuclear SphK2 may also regulate cyclin-dependent kinase inhibitor p21 and transcription regulator c-fos activity $(15,29)$. The overexpression of SphK2 has been shown to stimulate the PMA-induced expression of c-fos mRNA, and, thus, indirectly influence a large group of genes controlled by c-fos $(15,29)$. The SphK2 regulation of $\mathrm{HDAC1}$-dependent deacetylation of histone $\mathrm{H} 3$ also results in repression of $p 21$ gene transcription, thus interfering with cell cycle progression and cellular senescence. The nuclear signalling of SphK is regulated by protein kinase D (PKD)-induced phosphorylation, which promotes its export from the nucleus (30).

\section{Dual mechanisms of S1P signalling: extracellular and intracellular effects}

The multifunctional signalling lipid, S1P, mediates the effects of numerous biological stimuli, including cytokines, growth factors and hormones $(8,33)$. S1P regulates diverse signalling 


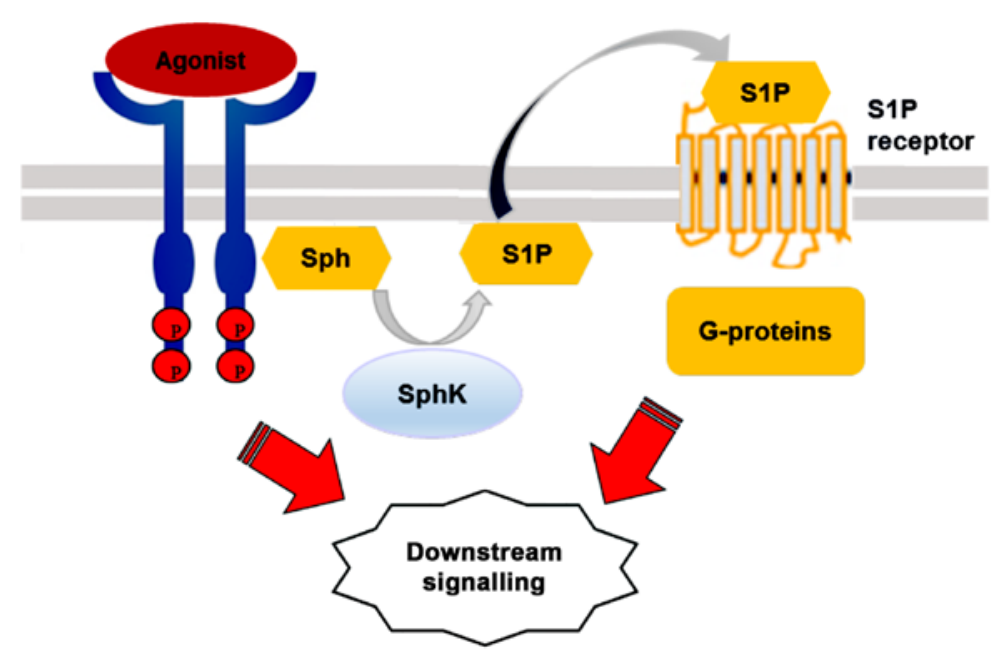

Figure 3. SphK/S1P pathway 'inside-out' signalling model. Various biologically stimulatory molecules bind and activate receptor tyrosine kinase that, in turn, induces the translocation of SphK1 from the cytosole to the plasma membrane. S1P is then locally produced and secreted from the cells. Extracellular S1P binds and activates S1P receptors to initiate further intracellular downstream signaling cascades such as cell proliferation, migration, and invasion. SphK, sphingosine kinase; S1P, sphingosine-1-phosphate; Sph, sphingosine.

via five transmembrane GPCRs, $\mathrm{S}_{1} \mathrm{P}_{1-5}$, originally known as endothelial differentiation gene (EDG) receptors (34). S1P may bind its receptors in a paracrine or autocrine manner, followed by differential coupling to specific $\mathrm{G}$ proteins (34).

According to the 'inside-out' signalling model, activated SphK1 is translocated to the plasma membrane where it generates S1P. The lipid is then released locally and, in an autocrine manner, binds to one or more S1P receptor subtypes on the same cell, or, in a paracrine manner, activates the receptors on neighbouring cells (33). Activated SphK1 may also be secreted from cells to produce S1P from extracellular Sph (35).

Amongst its intracellular targets, S1P has been shown to interact with several cytoplasmic and nuclear proteins (33), including HDAC1/2, which is involved in regulating histone acetylation and the epigenetic regulation of specific target genes, such as p21 and c-fos (36). S1P can also act as a co-factor, stimulating E3 ligase activity in TNF receptor-associated factor 2 (TRAF2) and controlling the survival response (37). Moreover, S1P interacts with inner mitochondrial membrane protein prohibitin 2 (PHB2) to regulate cytochrome $c$ oxidase assembly and mitochondrial respiration (38). Finally, S1P has been shown to bind the transcription factor peroxisome proliferator-activated receptor $\gamma$ (PPAR $\gamma$ ) (39), human telomerase reverse transcriptase (hTERT) (40) and beta-site amyloid precursor protein-cleaving enzyme 1 (BACE1) (41). The essential cellular effects of S1P are summarised in Fig. 3 and were recently reviewed in full detail elsewhere (42).

\section{The role of SphK/S1P signalling in the development of diabetes and related pathologies}

SphK signalling and hepatic insulin resistance. Reduced sensitivity to insulin of the hormone target tissues, such as skeletal muscle, liver and adipose deposits is defined as insulin resistance. Hepatic insulin resistance has been confirmed as the major risk factor for T2D onset. Previous studies have shown that SphK activation improves hepatic insulin signalling in obesity and diabetes $(43-45,47)$. Notably, in a previous study, low total SphK activity was detected in the livers of mice fed a high-fat diet (HFD). The mice also had elevated liver triacylglycerol (TAG) and diacylglycerol (DAG) levels, and demonstrated glucose intolerance. SphK1 overexpression in the liver reduced hepatic TAG synthesis and the total TAG content in the HFD-fed mice (46). However, these SphK1-overexpressing mice exhibited no changes in glucose metabolism, including the states of gluconeogenesis, glycogen synthesis and glucose tolerance (46), suggesting it has minimal influence on carbohydrate metabolism.

It was recently found that $\mathrm{SphK} 2$ is the major $\mathrm{SphK}$ isoform in the liver. The overexpression of the SphK2 gene has been shown to elevate hepatic S1P expression and improve glucose/lipid metabolism in KK/Ay diabetic mice. The adenoviral-mediated expression of SphK2 activated the Akt pathway, a key signalling mechanism in the insulin-induced regulation of glucose metabolism, thus, confirming an important role of SphK2 in regulating hepatic insulin signalling (47).

Insulin resistance is also associated with the pathological transformation of proteins and lipid biosynthesis in the EndRet. The perturbation of specific EndRet functions, the so-called EndRet stress, can be caused by excess nutrient intake (one of the major causes of obesity) that further induces the activation of multiple pathological chain-reaction mechanisms, including the unfolded protein response (UPR) and aberrant lipid biosynthesis (48). Notably, SphK/S1P-signalling activation ameliorates hepatic insulin resistance induced by EndRet stress. Accordingly, SphK2 activation improves insulin signalling and its metabolic actions under conditions of EndRet stress in HFD-fed mice. Activated SphK2 also reduces hepatic lipid accumulation, thus improving the effects of insulin in these mice in vivo, an effect confirmed in vitro in primary hepatocytes (47).

SphK signalling and pancreatic $\beta$-cell death. Decreased insulin secretion and T2D can be triggered by pancreatic $\beta$-cell death that is often caused by excessive levels of circulating lipids (lipotoxicity) in obese or overweight patients. Increased 
sphingolipid metabolites that are observed during lipotoxicity also induce $\beta$-cell dysfunction, leading to apoptosis (49). For example, increased intracellular ceramide promotes an apoptotic cascade and initiates $\beta$-cell death in diabetic fatty rodent models of T2D in vivo and human $\beta$-cells in vitro (50-52).

Caspase activation mediates ceramide-induced apoptosis (53). Studies using the MIN6 insulinoma cell line and INS-1 cells, which are used as cell models of glucolipotoxicity, have demonstrated that caspases-3/7 are activated during apoptosis initiated by increased levels of intracellular ceramide $(54,55)$. In addition to triggering apoptosis, ceramide has been shown to induce EndRet stress followed by insulin resistance in MIN6 cells in vitro (54). Insulin resistance initiated by ceramide treatment has been shown to be accompanied by reduced proinsulin mRNA levels in INS-1 cells and isolated rat pancreatic islets in vivo $(56,57)$. The process is marked by attenuated ERK1/2 signalling (57). Thus, elevated ceramide accumulation in pancreatic cells promoted insulin resistance and $\beta$-cell death. However, the detailed mechanisms of ceramide signalling and the development of associated pancreatic pathologies require further investigation.

Contrary to the deleterious effect of ceramide, SphK/S1P have been shown to promote insulin release, to stimulate the development of intra-islet vasculature, improve glucose sensing and prevent inflammation-linked attacks of the immune system (58). The relative intracellular balance of sphingolipid species, such as ceramide and S1P critically determines the direction of $\beta$-cell fate; deciding between activating apoptosis or proliferation, or stimulating insulin secretion, and/or islet-cell inflammatory responses (49).

There is abundant evidence demonstrating the pro-survival role of S1P in pancreatic $\beta$-cells. S1P has been shown to improve $\beta$-cell function in the HIT-T15 cell line and isolated mouse islets, through phospholipase C (PLC) activation (59). S1P has also been shown to protect pancreatic islet cells from IL-1 $\beta$-induced apoptosis (60). The exposure of INS-1 cells and isolated pancreatic islets to IL-1 $\beta$ and TNF- $\alpha$ has been shown to activate SphK 2 as a self-protective mechanism, reducing $\beta$-cell inflammatory damage (61). Furthermore, SphK1 activation promotes $\beta$-cell survival in diabetic obese mice in vivo (10). The roles of SphK/S1P in $\beta$-cell survival processes have also been addressed in several cell lines and animal models following lipotoxicity-induced $\beta$-cell damage. It was previously demonstrated that the inhibition of SphK/S1P signalling, activated in INS-1 $\beta$-cells by palmitate treatment, potentiated $\beta$-cell apoptosis; however, SphK1 overexpression significantly mitigated $\beta$-cell apoptosis under lipotoxic conditions (62). In another study, the assessment of SphK1(-/-) and wild-type HFD-fed mice demonstrated that HFD-fed SphK1(-/-) mice developed evident diabetes, accompanied by reduced $\beta$-cell mass and a 3-fold decrease in insulin secretion (10). Furthermore, the oral administration of FTY720 (a S1P receptor agonist) to diabetic $(\mathrm{db} / \mathrm{db})$ mice facilitated $\beta$-cell mass preservation and normalised fasting blood glucose $(48,63)$. In addition to its pro-survival effect, SphK activation has been shown to promote glucose-stimulated insulin secretion (GSIS) in MIN6 cells and mouse pancreatic islets (64).

SphK activation and S1P formation have recently been linked to endogenic adiponectin signalling during the induction of $\beta$-cell survival. The pro-survival effect of adiponectin has been shown to be modulated by increased S1P formation, employing the AMP-activated protein kinase (AMPK)-dependent pathway in obese mice $(44,65)$. Supporting these findings, S1P2 receptor inhibition has been shown to attenuate streptozotocin (STZ)-induced $\beta$-cell apoptosis in T1D models (66). Collectively, current studies indicate divergent signalling mechanisms and positive involvement of the different SphK isoforms and S1P receptor subtypes in protecting pancreatic $\beta$ cells from apoptosis and malfunction.

Sphingolipid signalling and the development of peripheral insulin resistance. Skeletal muscles consume energy and provide a sink for insulin-stimulated glucose disposal and glycogen formation, thus contributing to the regulation of whole body metabolism. Skeletal muscle insulin resistance is often considered to be the initiating event for T2D, evident prior to $\beta$-cell failure and overt hyperglycaemia. Previous studies have implicated SphK/S1P signalling in skeletal muscle insulin resistance, followed by decreased whole-body insulin sensitivity $(67,68)$. Notably, SphK1 overexpression promotes basal and insulin-stimulated glucose uptake in $\mathrm{C} 2 \mathrm{C} 12$ cells (67) and a remarkable reduction in blood glucose in diabetic mice $(12,67)$. In support of this, pharmacological SphK inhibition reduces insulin-stimulated glucose disposal (69).

Rapizzi et al reported that S1P induced ligand-independent trans-phosphorylation of the insulin receptor and increased glucose uptake in $\mathrm{C} 2 \mathrm{C} 12$ myoblasts (70). The same group illustrated the involvement of SphK in a positive feedback loop during the sustained activation of insulin receptor involvement (71). Taking into account the negative effects of ceramide in the development of insulin resistance, it is important to determine whether improved insulin signalling in skeletal muscle is a consequence of SphK overexpression/activation or the result of reduced ceramide intracellular levels.

Bruce et al demonstrated that the overexpression of SphK improved skeletal muscle insulin sensitivity and decreased intracellular ceramide in transgenic mice, although S1P abundance was only moderately increased, or remained unaltered (12). Moreover, Takuwa et al reported that SphK overexpression only moderately enhanced S1P in the tissues of transgenic mice, suggesting that decreased ceramide is the main mechanism for SphK-dependent regulation of insulin sensitivity (72).

The adiponectin receptor is another alternative mechanism potentially explaining the protective effects of SphK. The overexpression of the adiponectin receptor AdipR1 improves local insulin sensitivity in rat skeletal muscle, at the same time reducing the concentration of both S1P and ceramide (73). Overall, experimental findings suggest a fundamental role of SphK signalling as a tool for ceramide utilisation and the modulation of skeletal muscle insulin resistance. However, the contribution of S1P to skeletal muscle insulin resistance requires further clarification.

Intriguingly, despite intensive research in the field, the role of SphK/S1P signalling in regulating insulin sensitivity remains controversial, as alternative studies demonstrate the pro-inflammatory effects of the SphK/S1P pathway. However, it is well established that obesity and adipocyte-triggered inflammation give rise to insulin resistance in peripheral tissues, and that SphK1 signalling mediates lipolysis-associated inflamma- 
tion in adipocytes. Excessive lipolysis can induce inflammation via the increased production of inflammatory cytokines, such as IL- 6 and/or the acute activation of $\beta 3$-adrenergic receptors. The pharmacological inhibition of SphK1 activity blocks ADRB3-induced IL-6 production in adipocytes, both in vitro and in vivo (74). Furthermore, the selective inhibition of SphK1 protects adipocytes from lipopolysaccharide (LPS)-induced inflammation in Zucker diabetic fatty rats (75). SphK1 deficiency upregulates the gene expression of the anti-inflammatory molecules (IL-10 and adiponectin) and improves overall insulin sensitivity in the adipose and muscle tissues of SphK1 knockout mice in vivo (68). Further detailed investigations of the involvement of SphK in inflammatory processes are required. However, taken together, the accumulating evidence indicates that the inhibition of the SphK/S1P axis is a potential therapeutic target for the treatment of insulin resistance.

\section{The role of SphKs in the progression of diabetes-related complications}

SphK/S1P signalling has been linked to several diabetic microvascular complications, such as neuropathy (76-78), retinopathy $(79,80)$ and nephropathy $(81)$.

SphK signalling and diabetic nephropathy (DN). Aberrant sphingolipid metabolism and/or generation of specific sphingolipid metabolites are thought to aggravate diabetic complications, including the pathogenesis of DN. DN is characterised by a series of pathological events, such as early glomerular proliferation and hypertrophy, accumulation of extracellular matrix (ECM) components and renal fibrosis that may progress to end-stage renal disease. The incidence of DN accounts for $30 \%$ of diabetic patients diagnosed with glomerular sclerosis and/or tubulointerstitial (renal) fibrosis (82). S1P stimulates the survival, proliferation and migration of renal mesangial cells $(83,84)$, and induces the upregulation of the pro-fibrotic growth factors, collagen and fibronectin synthesis $(81,85)$. Phosphorylated Smads, secreted phospholipase A2 and matrix metalloproteinase- 9 mediate the effect of $\mathrm{S} 1 \mathrm{P}$ in renal cells $(81,85)$.

SphK/S1P signalling has previously been linked to glomerular proliferation. However, S1P can promote not only renal mesangial cell proliferation, but also renal inflammation and fibrosis (86). The stimulatory effect of S1P on renal mesangial cell proliferation was first demonstrated in Swiss 3 T3 fibroblasts (87). In a previous study, activated SphK and 10-fold upregulated S1P levels stimulated the proliferation of glomerular mesangial cells in rats with STZ-induced diabetes in vivo (88). Further studies have confirmed an association of SphK1 activation and S1P production with renal hypertrophy and increased levels of fibronectin $(81,89)$. SphK1/S1P promotes glomerular mesangial cell proliferation via increased fibronectin production, but also through the activation of transforming growth factor- $\beta 1$ (TGF- $\beta 1$ ) and AP-1 signalling (90).

Expressed in glomerular mesangial cells, S1P2 and S1P3 receptors mediate renal fibrosis, glomerular cell proliferation and pathological angiogenesis $(91,92)$. Lymphocyte migration to the site of inflammation is mediated through binding to the S1P1 receptor (93), indicating the involvement of this receptor subtype in potentially damaging immune reactions in kidneys and other organs (94-96). However, an inflammation-associated role of the SphK/S1P pathway remains controversial, as other authors have demonstrated that S1P can reduce inflammatory signals in cultured renal mesangial cells by downregulating prostaglandin E2 synthesis and the expression of pro-inflammatory mediators, such as cytokine-triggered secretory phospholipase A2 and inducible nitric oxide (NO) synthase (97).

The relevance of $\mathrm{SphK} / \mathrm{S} 1 \mathrm{P}$ signalling to $\mathrm{DN}$ progression was investigated in SphK-deficient mice in vivo (35). One study on SphK2-deficient mice showed reduced plasma creatinine concentrations, suggesting that SphK2 protected cells from renal ischaemia (98), and another study detected the worsening of nephropathy conditions in SphK1-deficient mice (86). The loss of SphK1 activity has been shown to aggravate cytogenesis in a mouse model of polycystic kidney disease and renal injury (35). Similarly, the lentiviral-mediated overexpression of human SphK1 in mice subjected to ischaemia-perfusion injury demonstrated less tubular necrosis and reduced inflammation (98). Overall, the current evidence suggests the involvement of both SphK isoforms, probably to a different degree and affecting distinct targets, in regulating microvascular complications, such as DN. Further studies are warranted in order to clarify which SphK isoform is involved in inflammation-associated signalling and whether S1P receptors should be targeted for nephropathy drug design.

Involvement of the SphK/S1P signalling in diabetes-related vascular complications. The risks of cardiovascular disease, atherosclerosis $(99,100)$ and heart failure are critically elevated in patients with diabetes (99-104). Multiple studies have indicated a cardioprotective role of SphK/S1P pathway activation in vivo (67,105-107). In a diabetic mouse model with increased myocardial glycogen accumulation leading to cardiomyopathy, SphK1 overexpression was shown to improve heart function (67). With regard to atherosclerotic complications, S1P reduces glucose-stimulated monocyte-endothelial interaction in the non-obese diabetic mouse model NOD/LtJ $(108,109)$.

Diabetic patients commonly present with silent myocardial ischaemia (110). SphK1 activation has been shown to protect isolated mouse hearts against ischaemia-associated injury $(94,111,112)$ and promotes the recovery of haemodynamic function following ischaemic injury (94). Pharmacological SphK inhibition with $N, N$-dimethylsphingosine (DMS) confirms the SphK-linked protection of murine hearts against ischemia/reperfusion injury employing protein kinase CE-dependent mechanisms (95). The overexpression of SphK1 mediates myocardial ischaemic preconditioning-induced cardioprotection in murine hearts (96). SphK1 is also important maintaining the blood vessel integrity (113) and the wound healing process in diabetic rats (114). On the other hand, SphK1 inhibition ameliorates angiotensin II-induced acute hypertension, suggesting a negative influence of SphK on vascular health (115).

However, several recent investigations have indicated a positive effect of S1P receptor signalling in maintaining vascular health. The transactivation of $\mathrm{S} 1 \mathrm{P} 1 / 3$ receptors stimulates eNOS, increasing NO production and vasodilation $(116,117)$. The increased expression of $\mathrm{S} 1 \mathrm{P} 1 / 3$ receptors improves recovery following cardiac microvascular dysfunc- 
tion associated with diabetes (118). The S1P1 receptor also mediates estrogen-induced activation of Akt/eNOS signalling in endothelial cells (119). Estrogen replacement therapy in post-menopausal women prevents diabetes-associated cardiovascular complications (120), thus indicating that S1P receptors should be further explored as potential drug targets for the treatment of diabetes-associated vascular pathologies.

\section{Summary}

The complex interactions among members of the sphingolipid signalling pathway, insulin signalling and diabetic pathologies have been extensively investigated. Yet the role of SphK/S1P signalling in the development of diabetes mellitus remains unclear. The divergence of SphK/S1P signalling seems to be dependent on cell type, the expression pattern of S1P receptor subtypes and the relative expression of the specific SphK isoforms. In diabetes mellitus, SphK activation has been known to promote $\beta$-cell survival and insulin secretion, prevent vascular pathologies related to diabetes $(39,116,119)$, ameliorate peripheral insulin resistance and obesity in diabetic patients and animal models $(121,122)$.A low S1P content has been linked to increased incidence of coronary artery disease $(97,122-124)$ and diabetes mellitus (97,125-127).

In addition, emerging evidence has also linked SphK/S1P signalling to the development of diabetes-related vascular complications, such as neuropathy (76-78), retinopathy $(79,80,128,129)$ and nephropathy $(81)$. However, the roles of the different S1P receptor subtypes and two SphK isoforms in the pathogenesis of diabetes remain to be confirmed in vivo and in future clinical trials. SphK therefore represents a potential therapeutic target for diabetes mellitus. The FTY720 (fingolimoid), an S1P receptor agonist has demonstrated promising therapeutic effects, including the stimulation of lipolysis, decreased accumulation of skeletal muscle ceramide, improved systemic glucose homeostasis, and $\beta$-cell survival in diabetic mouse models $(63,118,130)$. Combination therapy with FTY720 plus insulin glargine has been shown to be a promising therapeutic strategy for the treatment of diabetes mellitus (130). A second generation of S1P3 modulators (siponimod, ponesimod, KRP-203, ONO-4641, RPC1063, CS-0777 and GSK2018682) targets different S1P receptor subtypes (131). These substances promise to elucidate the mechanisms underlying the divergent outcomes of S1P signalling, and consequently, the potential efficacy of targeting the SphK/S1P pathway for the treatment of diabetes and associated pathologies.

\section{References}

1. Danaei G, Finucane MM, Lu Y, Singh GM, Cowan MJ, Paciorek CJ, Lin JK, Farzadfar F, Khang YH, Stevens GA, et al; Global Burden of Metabolic Risk Factors of Chronic Diseases Collaborating Group (Blood Glu-cose): National, regional, and global trends in fasting plasma glucose and diabetes prevalence since 1980: Systematic analysis of health examination surveys and epidemiological studies with 370 country-years and $2 \cdot 7$ million participants. Lancet 378: 31-40, 2011.

2. Expert Committee on the Diagnosis and Classification of Diabetes Mellitus: Report of the expert committee on the diagnosis and classification of diabetes mellitus. Diabetes Care 26 (Suppl 1): S5-S20, 2003.

3. Shao S, Yang Y, Yuan G,Zhang M and Yu X: Signaling molecules involved in lipid-induced pancreatic beta-cell dysfunction. DNA Cell Biol 32: 41-49, 2013.
4. Newsholme P, Keane D, Welters HJ and Morgan NG: Life and death decisions of the pancreatic beta-cell: The role of fatty acids. Clin Sci (Lond) 112: 27-42, 2007.

5. Alemany R, van Koppen CJ, Danneberg K, Ter Braak M and Meyer zu Heringdorf D: Regulation and functional roles of sphingosine kinases. Naunyn Schmiedebergs Arch Pharmacol 374: 413-428, 2007.

6. Van Brocklyn JR, Lee MJ, Menzeleev R, Olivera A, Edsall L, Cuvillier O, Thomas DM, Coopman PJ, Thangada S, Liu CH, et al: Dual actions of sphingosine-1-phosphate: Extracellular through the Gi-coupled receptor Edg-1 and intracellular to regulate proliferation and survival. J Cell Biol 142: 229-240, 1998.

7. Olivera A and Spiegel S: Sphingosine-1-phosphate as second messenger in cell proliferation induced by PDGF and FCS mitogens. Nature 365: 557-560, 1993.

8. Cuvillier O, Pirianov G, Kleuser B, Vanek PG, Coso OA, Gutkind S and Spiegel S: Suppression of ceramide-mediated programmed cell death by sphingosine-1-phosphate. Nature 381: 800-803, 1996.

9. Pyne S, Chapman J, Steele L and Pyne NJ: Sphingomyelin-derived lipids differentially regulate the extracellular signal-regulated kinase 2 (ERK-2) and c-Jun N-terminal kinase (JNK) signal cascades in airway smooth muscle. Eur J Biochem 237: 819-826, 1996.

10. Qi Y, Chen J, Lay A, Don A, Vadas M and Xia P: Loss of sphingosine kinase 1 predisposes to the onset of diabetes via promoting pancreatic $\beta$-cell death in diet-induced obese mice. FASEB J 27: 4294-4304, 2013.

11. Holland WL, Brozinick JT, Wang LP, Hawkins ED, Sargent KM, Liu Y, Narra K, Hoehn KL, Knotts TA, Siesky A, et al: Inhibition of ceramide synthesis ameliorates glucocorticoid-, saturated-fat-, and obesity-induced insulin resistance. Cell Metab 5: 167-179, 2007.

12. Bruce CR, Risis S, Babb JR, Yang C, Kowalski GM, Selathurai A Lee-Young RS, Weir JM, Yoshioka K, Takuwa Y, et al: Overexpression of sphingosine kinase 1 prevents ceramide accumulation and ameliorates muscle insulin resistance in high-fat diet-fed mice. Diabetes 61: 3148-3155, 2012.

13. Spiegel S and Milstien S: The outs and the ins of sphingosine-1-phosphate in immunity. Nat Rev Immunol 11: 403-415, 2011.

14. Pyne S and Pyne NJ: Translational aspects of sphingosine 1-phosphate biology. Trends Mol Med 17: 463-472, 2011.

15. Maceyka M and Spiegel S: Sphingolipid metabolites in inflammatory disease. Nature 510: 58-67, 2014.

16. Mendelson K, Evans T and Hla T: Sphingosine 1-phosphate signalling. Development 141: 5-9, 2014.

17. Hla T and Dannenberg AJ: Sphingolipid signaling in metabolic disorders. Cell Metab 16: 420-434, 2012.

18. Pitson SM: Regulation of sphingosine kinase and sphingolipid signaling. Trends Biochem Sci 36: 97-107, 2011.

19. Don AS and Rosen H: A lipid binding domain in sphingosine kinase 2. Biochem Biophys Res Commun 380: 87-92, 2009.

20. Barr RK, Lynn HE, Moretti PA, Khew-Goodall Y and Pitson SM: Deactivation of sphingosine kinase 1 by protein phosphatase $2 \mathrm{~A}$. J Biol Chem 283: 34994-35002, 2008.

21. Sutherland CM, Moretti PA, Hewitt NM, Bagley CJ, Vadas MA and Pitson SM: The calmodulin-binding site of sphingosine kinase and its role in agonist-dependent translocation of sphingosine kinase 1 to the plasma membrane. J Biol Chem 281: 11693-11701, 2006.

22. Hait NC, Allegood J, Maceyka M, Strub GM, Harikumar KB, Singh SK, Luo C, Marmorstein R, Kordula T, Milstien S and Spiegel S: Regulation of histone acetylation in the nucleus by sphingosine-1-phosphate. Science 325: 1254-1257, 2009.

23. Wattenberg BW, Pitson SM and Raben DM: The sphingosine and diacylglycerol kinase superfamily of signaling kinases: Localization as a key to signaling function. J Lipid Res 47: 1128-1139, 2006.

24. Leclercq TM and Pitson SM: Cellular signalling by sphingosine kinase and sphingosine 1-phosphate. IUBMB Life 58: 467-472, 2006.

25. Giussani P, Maceyka M, Le Stunff H, Mikami A, Lépine S, Wang E, Kelly S, Merrill AH Jr, Milstien S and Spiegel S: Sphingosine-1-phosphate phosphohydrolase regulates endoplasmic reticulum-to-golgi trafficking of ceramide. Mol Cell Biol 26: 5055-5069, 2006.

26. Pitson SM, Moretti PA, Zebol JR, Lynn HE, Xia P, Vadas MA and Wattenberg BW: Activation of sphingosine kinase 1 by ERK1/2-mediated phosphorylation. EMBO J 22: 5491-5500, 2003. 
27. Stahelin RV, Hwang JH, Kim JH, Park ZY, Johnson KR, Obeid LM and Cho W: The mechanism of membrane targeting of human sphingosine kinase 1. J Biol Chem 280: 43030-43038, 2005.

28. Siow D and Wattenberg B: The compartmentalization and translocation of the sphingosine kinases: Mechanisms and functions in cell signaling and sphingolipid metabolism. Crit Rev Biochem Mol Biol 46: 365-375, 2011.

29. Maceyka M, Sankala H, Hait NC, Le Stunff H, Liu H, Toman R, Collier C, Zhang M, Satin LS, Merrill AH Jr, et al: SphK1 and SphK2, sphingosine kinase isoenzymes with opposing functions in sphingolipid metabolism. J Biol Chem 280: 37118-37129, 2005.

30. Ding G, Sonoda H, Yu H, Kajimoto T, Goparaju SK, Jahangeer S, Okada T and Nakamura S: Protein kinase D-mediated phosphorylation and nuclear export of sphingosine kinase 2. J Biol Chem 282: 27493-27502, 2007.

31. Igarashi N, Okada T, Hayashi S, Fujita T, Jahangeer S and Nakamura S: Sphingosine kinase 2 is a nuclear protein and inhibits DNA synthesis. J Biol Chem 278: 46832-46839, 2003.

32. Hait NC, Bellamy A, Milstien S, Kordula T and Spiegel S: Sphingosine kinase type 2 activation by ERK-mediated phosphorylation. J Biol Chem 282: 12058-12065, 2007.

33. Alvarez SE, Milstien S and Spiegel S: Autocrine and paracrine roles of sphingosine-1-phosphate. Trends Endocrinol Metab 18: 300-307, 2007.

34. Strub GM, Maceyka M, Hait NC, Milstien S and Spiegel S: Extracellular and intracellular actions of sphingosine-1-phosphate. Adv Exp Med Biol 688: 141-155, 2010.

35. Venkataraman K, Thangada S, Michaud J, Oo ML, Ai Y, Lee YM, Wu M, Parikh NS, Khan F, Proia RL and Hla T: Extracellular export of sphingosine kinase-la contributes to the vascular S1P gradient. Biochem J 397: 461-471, 2006.

36. Maceyka M, Harikumar KB, Milstien S and Spiegel S: Sphingosine-1-phosphate signaling and its role in disease. Trends Cell Biol 22: 50-60, 2012.

37. Xia P, Wang L, Moretti PA, Albanese N, Chai F, Pitson SM, D'Andrea RJ, Gamble JR and Vadas MA: Sphingosine kinase interacts with TRAF2 and dissects tumor necrosis factor-alpha signaling. J Biol Chem 277: 7996-8003, 2002.

38. Artal-Sanz M and Tavernarakis N: Prohibitin and mitochondrial biology. Trends Endocrinol Metab 20: 394-401, 2009.

39. Parham KA, Zebol JR, Tooley KL, Sun WY, Moldenhauer LM, Cockshell MP, Gliddon BL, Moretti PA, Tigyi G, Pitson SM and Bonder CS: Sphingosine 1-phosphate is a ligand for peroxisome proliferator-activated receptor- $\gamma$ that regulates neoangiogenesis. FASEB J 29: 3638-3653, 2015.

40. Panneer Selvam S, De Palma RM, Oaks JJ, Oleinik N, Peterson YK, Stahelin RV, Skordalakes E, Pon-nusamy S, Garrett-Mayer E, Smith CD and Ogretmen B: Binding of the sphingolipid S1P to hTERT stabilizes telomerase at the nuclear periphery by allosterically mimicking protein phosphorylation. Sci Signal 8: ra58, 2015.

41. Takasugi N, Sasaki T, Suzuki K, Osawa S, Isshiki H, Hori Y, Shimada N, Higo T, Yokoshima S, Fukuyama T, et al: BACE1 activity is modulated by cell-associated sphingosine-1-phosphate. J Neurosci 31: 6850-6857, 2011.

42. Pyne S, Adams DR and Pyne NJ: Sphingosine 1-phosphate and sphingosine kinases in health and disease: Recent advances. Prog Lipid Res 62: 93-106, 2016.

43. Fox TE, Bewley MC, Unrath KA, Pedersen MM, Anderson RE, Jung DY, Jefferson LS, Kim JK, Bronson SK, Flanagan JM, et al Circulating sphingolipid biomarkers in models of type 1 diabetes. J Lipid Res 52: 509-517, 2011.

44. Tao C, Sifuentes A and Holland WL: Regulation of glucose and lipid homeostasis by adiponectin: Effects on hepatocytes, pancreatic $\beta$ cells and adipocytes. Best Pract Res Clin Endocrinol Metab 28: 43-58, 2014.

45. Osawa Y, Seki E, Kodama Y, Suetsugu A, Miura K, Adachi M, Ito H, Shiratori Y, Banno Y, Olefsky JM, et al: Acid sphingomyelinase regulates glucose and lipid metabolism in hepatocytes through AKT activation and AMP-activated protein kinase suppression. FASEB J 25: 1133-1144, 2011.

46. Kowalski GM, Kloehn J, Burch ML, Selathurai A, Hamley S, Bayol SA, Lamon S, Watt MJ, Lee-Young RS, McConville MJ and Bruce CR: Overexpression of sphingosine kinase 1 in liver reduces triglyceride content in mice fed a low but not high-fat diet. Biochim Biophys Acta 1851: 210-219, 2015.

47. Lee SY, Hong IK, Kim BR, Shim SM, Sung Lee J, Lee HY, Soo Choi C, Kim BK and Park TS: Activation of sphingosine kinase 2 by endoplasmic reticulum stress ameliorates hepatic steatosis and insulin resistance in mice. Hepatology 62: 135-146, 2015.
48. Boden G: Endoplasmic reticulum stress: Another link between obesity and insulin resistance/inflammation? Diabetes 58: 518-519, 2009.

49. Boslem E, Meikle PJ and Biden TJ: Roles of ceramide and sphingolipids in pancreatic $\beta$-cell function and dysfunction. Islets 4 : 177-187, 2012.

50. Zhu Q, Shan X, Miao H, Lu Y, Xu J, You N, Liu C, Liao DF and Jin $\mathrm{J}$ : Acute activation of acid ceramidase affects cytokine-induced cytotoxicity in rat islet beta-cells. FEBS Lett 583: 2136-2141, 2009

51. Maedler K, Oberholzer J, Bucher P, Spinas GA and Donath MY: Monounsaturated fatty acids prevent the deleterious effects of palmitate and high glucose on human pancreatic beta-cell turnover and function. Diabetes 52: 726-733, 2003.

52. Veluthakal R, Palanivel R, Zhao Y, McDonald P, Gruber S and Kowluru A: Ceramide induces mitochondrial abnormalities in insulin-secreting INS-1 cells: Potential mechanisms underlying ceramide-mediated metabolic dysfunction of the beta cell. Apoptosis 10: 841-850, 2005.

53. Lupi R, Dotta F, Marselli L, Del Guerra S, Masini M, Santangelo C, Patané G, Boggi U, Piro S, Anello M, et al: Prolonged exposure to free fatty acids has cytostatic and pro-apoptotic effects on human pancreatic islets: Evidence that beta-cell death is caspase mediated, partially dependent on ceramide pathway, and Bcl-2 regulated. Diabetes 51: 1437-1442, 2002.

54. Boslem E, MacIntosh G, Preston AM, Bartley C, Busch AK, Fuller M, Laybutt DR, Meikle PJ and Biden TJ: A lipidomic screen of palmitate-treated MIN6 $\beta$-cells links sphingolipid metabolites with endoplasmic reticulum (ER) stress and impaired protein trafficking. Biochem J 435: 267-276, 2011.

55. Véret J, Coant N, Berdyshev EV, Skobeleva A, Therville N, Bailbé D, Gorshkova I, Natarajan V, Portha B and Le Stunff H: Ceramide synthase 4 and de novo production of ceramides with specific $\mathrm{N}$-acyl chain lengths are involved in glucolipotoxicity-induced apoptosis of INS-1 $\beta$-cells. Biochem J 438: 177-189, 2011.

56. Kelpe CL, Moore PC, Parazzoli SD, Wicksteed B, Rhodes CJ and Poitout V: Palmitate inhibition of insulin gene expression is mediated at the transcriptional level via ceramide synthesis. J Biol Chem 278: 30015-30021, 2003.

57. Guo J, Qian Y, Xi X, Hu X, Zhu J and Han X: Blockage of ceramide metabolism exacerbates palmitate inhibition of pro-insulin gene expression in pancreatic beta-cells. Mol Cell Biochem 338: 283-290, 2010.

58. Jessup CF, Bonder CS, Pitson SM and Coates PT: The sphingolipid rheostat: A potential target for improving pancreatic islet survival and function. Endocr Metab Immune Disord Drug Targets 11: 262-272, 2011.

59. Shimizu H, Okajima F, Kimura T, Ohtani K, Tsuchiya T, Takahashi H, Kuwabara A, Tomura H, Sato K and Mori M: Sphingosine 1-phosphate stimulates insulin secretion in HIT-T 15 cells and mouse islets. Endocr J 47: 261-269, 2000.

60. Rütti S, Ehses JA, Sibler RA, Prazak R, Rohrer L, Georgopoulos S, Meier DT, Niclauss N, Berney T, Donath MY, et al: Low- and high-density lipoproteins modulate function, apoptosis, and proliferation of primary human and murine pancreatic beta-cells. Endocrinology 150: 4521-4530, 2009.

61. Mastrandrea LD, Sessanna SM and Laychock SG: Sphingosine kinase activity and sphingosine-1 phosphate production in rat pancreatic islets and INS-1 cells: Response to cytokines. Diabetes 54: 1429-1436, 2005.

62. Véret J, Coant N, Gorshkova IA, Giussani P, Fradet M, Riccitelli E, Skobeleva A, Goya J, Kassis N, Natarajan V, et al: Role of palmitate-induced sphingoid base-1-phosphate biosynthesis in INS-1 $\beta$-cell survival. Biochim Biophys Acta 1831: 251-262, 2013.

63. Zhao Z, Choi J, Zhao C and Ma ZA: FTY720 normalizes hyperglycemia by stimulating $\beta$-cell in vivo re-generation in $\mathrm{db} / \mathrm{db}$ mice through regulation of cyclin D3 and p57(KIP2). J Biol Chem 287: 5562-5573, 2012.

64. Cantrell Stanford J, Morris AJ, Sunkara M, Popa GJ, Larson KL and Özcan S: Sphingosine 1-phosphate (S1P) regulates glucose-stimulated insulin secretion in pancreatic beta cells. J Biol Chem 287: 13457-13464, 2012.

65. Holland WL, Miller RA, Wang ZV, Sun K, Barth BM, Bui HH, Davis KE, Bikman BT, Halberg N, Rutkowski JM, et al: Receptor-mediated activation of ceramidase activity initiates the pleiotropic actions of adiponectin. Nat Med 17: 55-63, 2011. 
66. Imasawa T, Koike K, Ishii I, Chun J and Yatomi Y: Blockade of sphingosine 1-phosphate receptor 2 signaling attenuates streptozotocin-induced apoptosis of pancreatic beta-cells. Biochem Biophys Res Commun 392: 207-211, 2010.

67. Ma MM, Chen JL, Wang GG, Wang H, Lu Y, Li JF, Yi J, Yuan YJ, Zhang QW, Mi J, et al: Sphingosine kinase 1 participates in insulin signalling and regulates glucose metabolism and homeostasis in KK/Ay diabetic mice. Diabetologia 50: 891-900, 2007.

68. Wang J, Badeanlou L, Bielawski J, Ciaraldi TP and Samad F: Sphingosine kinase 1 regulates adipose proinflammatory responses and insulin resistance. Am J Physiol Endocrinol Metab 306: E756-E768, 2014.

69. Mikłosz A, Łukaszuk B, Baranowski M, Górski J and Chabowski A: Effects of inhibition of serine palmitoyltransferase (SPT) and sphingosine kinase 1 (SphK1) on palmitate induced insulin resistance in L6 myotubes. PLoS One 8: e85547, 2013.

70.Rapizzi E, Taddei ML, Fiaschi T, Donati C, Bruni P and Chiarugi P: Sphingosine 1-phosphate increases glucose uptake through trans-activation of insulin receptor. Cell Mol Life Sci 66: 3207-3218, 2009.

71.Rapizzi E, Donati C, Cencetti F, Nincheri P and Bruni P: Sphingosine 1-phosphate differentially regulates proliferation of $\mathrm{C} 2 \mathrm{C} 12$ reserve cells and myoblasts. Mol Cell Biochem 314: 193-199, 2008.

72. Takuwa N, Ohkura S, Takashima S, Ohtani K, Okamoto Y, Tanaka T, Hirano K, Usui S, Wang F, Du W, et al: S1P3-mediated cardiac fibrosis in sphingosine kinase 1 transgenic mice involves reactive oxygen species. Cardiovasc Res 85: 484-493, 2010.

73. Patel SA, Hoehn KL, Lawrence RT, Sawbridge L, Talbot NA, Tomsig JL, Turner N, Cooney GJ, Whitehead JP, Kraegen EW and Cleasby ME: Overexpression of the adiponectin receptor AdipoR1 in rat skeletal muscle amplifies local insulin sensitivity. Endocrinology 153: 5231-5246, 2012.

74.Zhang W, Mottillo EP, Zhao J, Gartung A, VanHecke GC Lee JF, Maddipati KR, Xu H, Ahn YH, Proia RL, et al: Adipocyte lipolysis-stimulated interleukin- 6 production requires sphingosine kinase 1 activity. J Biol Chem 289: 32178-32185, 2014.

75. Tous M, Ferrer-Lorente R and Badimon L: Selective inhibition of sphingosine kinase-1 protects adipose tissue against LPS-induced inflammatory response in Zucker diabetic fatty rats. Am J Physiol Endocrinol Metab 307: E437-E446, 2014

76. Janes K, Little JW, Li C, Bryant L, Chen C, Chen Z, Kamocki K, Doyle T, Snider A, Esposito E, et al: The development and maintenance of paclitaxel-induced neuropathic pain require activation of the sphingosine 1-phosphate receptor subtype 1. J Biol Chem 289: 21082-21097, 2014

77. Guan H, Song L, Cai J, Huang Y, Wu J, Yuan J, Li J and Li M: Sphingosine kinase 1 regulates the Akt/FOXO3a/Bim pathway and contributes to apoptosis resistance in glioma cells. PLoS One 6: e19946, 2011

78. Abuhusain HJ, Matin A, Qiao Q, Shen H, Kain N, Day BW, Stringer BW, Daniels B, Laaksonen MA, Teo C, et al: A metabolic shift favoring sphingosine 1-phosphate at the expense of ceramide controls glioblastoma angiogenesis. J Biol Chem 288: 37355-37364, 2013.

79. Xie B, Shen J, Dong A, Rashid A, Stoller G and Campochiaro PA: Blockade of sphingosine-1-phosphate reduces macrophage influx and retinal and choroidal neovascularization. J Cell Physiol 218: 192-198, 2009.

80. Maines LW, French KJ, Wolpert EB, Antonetti DA and Smith CD: Pharmacologic manipulation of sphingosine kinase in retinal endothelial cells: Implications for angiogenic ocular diseases. Invest Ophthalmol Vis Sci 47: 5022-5031, 2006.

81.Lan T, Liu W, Xie X, Xu S, Huang K, Peng J, Shen X, Liu P, Wang L, Xia P and Huang H: Sphingosine kinase-1 pathway mediates high glucose-induced fibronectin expression in glomerular mesangial cells. Mol Endocrinol 25: 2094-2105, 2011

82.Liu Y: Renal fibrosis: New insights into the pathogenesis and therapeutics. Kidney Int 69: 213-217, 2006.

83. Katsuma S, Hada Y, Ueda T, Shiojima S, Hirasawa A, Tanoue A, Takagaki K, Ohgi T, Yano J and Tsujimoto G: Signalling mechanisms in sphingosine 1-phosphate-promoted mesangial cell proliferation. Genes Cells 7: 1217-1230, 2002.

84. Klawitter S, Hofmann LP, Pfeilschifter J and Huwiler A: Extracellular nucleotides induce migration of renal mesangia cells by upregulating sphingosine kinase-1 expression and activity. Br J Pharmacol 150: 271-280, 2007.
85. Xin C, Ren S, Kleuser B, Shabahang S, Eberhardt W, Radeke $H$, Schäfer-Korting $M$, Pfeilschifter $J$ and Huwiler A: Sphingosine 1-phosphate cross-activates the Smad signaling cascade and mimics transforming growth factor-beta-induced cell responses. J Biol Chem 279: 35255-35262, 2004.

86. Yaghobian D, Don AS, Yaghobian S, Chen X, Pollock CA and Saad S: Increased sphingosine 1-phosphate mediates inflammation and fibrosis in tubular injury in diabetic nephropathy. Clin Exp Pharmacol Physiol 43: 56-66, 2016.

87. Spiegel S and Milstien S: Sphingosine-1-phosphate: An enigmatic signalling lipid. Nat Rev Mol Cell Biol 4: 397-407, 2003.

88. Geoffroy K, Troncy L, Wiernsperger N, Lagarde M and El Bawab S: Glomerular proliferation during early stages of diabetic nephropathy is associated with local increase of sphingosine-1-phosphate levels. FEBS Lett 579: 1249-1254, 2005.

89. Lan T, Shen X, Liu P, Liu W, Xu S, Xie X, Jiang Q, Li W and Huang $\mathrm{H}$ : Berberine ameliorates renal injury in diabetic C57BL/6 mice: Involvement of suppression of SphK-S1P signaling pathway. Arch Biochem Biophys 502: 112-120, 2010.

90. Huang K, Huang J, Chen C, Hao J, Wang S, Huang J, Liu P and Huang $\mathrm{H}$ : AP-1 regulates sphingosine kinase 1 expression in a positive feedback manner in glomerular mesangial cells exposed to high glucose. Cell Signal 26: 629-638, 2014.

91. Liu W, Lan T, Xie X, Huang K, Peng J, Huang J, Shen X, Liu P and Huang H: S1P2 receptor mediates sphingosine-1-phosphate-induced fibronectin expression via MAPK signaling pathway in mesangial cells under high glucose condition. Exp Cell Res 318: 936-943, 2012.

92. Imasawa T, Kitamura H, Ohkawa R, Satoh Y, Miyashita A and Yatomi Y: Unbalanced expression of sphingosine 1-phosphate receptors in diabetic nephropathy. Exp Toxicol Pathol 62: 53-60, 2010.

93. Xia P, Wang L, Gamble JR and Vadas MA: Activation of sphingosine kinase by tumor necrosis factor-alpha inhibits apoptosis in human endothelial cells. J Biol Chem 274: 34499-34505, 1999.

94. Vessey DA, Kelley M, Li L, Huang Y, Zhou HZ, Zhu BQ and Karliner JS: Role of sphingosine kinase activity in protection of heart against ischemia reperfusion injury. Med Sci Monit 12: BR318-BR324, 2006.

95. Jin ZQ and Karliner JS: Low dose $N, N$-dimethylsphingosine is cardioprotective and activates cytosolic sphingosine kinase by a PKCepsilon dependent mechanism. Cardiovasc Res 71: 725-734, 2006

96. Jin ZQ, Goetzl EJ and Karliner JS: Sphingosine kinase activation mediates ischemic preconditioning in murine heart. Circulation 110: 1980-1989, 2004.

97. Besler C, Heinrich K, Rohrer L, Doerries C, Riwanto M, Shih DM, Chroni A, Yonekawa K, Stein S, Schaefer N, et al: Mechanisms underlying adverse effects of HDL on eNOS-activating pathways in patients with coronary artery disease. J Clin Invest 121: 2693-2708, 2011.

98. Park SW, Kim M, Kim JY, Brown KM, Haase VH, D'Agati VD and Lee HT: Proximal tubule sphingosine kinase-1 has a critical role in A1 adenosine receptor-mediated renal protection from ischemia. Kidney Int 82: 878-891, 2012.

99. Paneni F, Beckman JA, Creager MA and Cosentino F: Diabetes and vascular disease: Pathophysiology, clinical consequences, and medical therapy: Part I. Eur Heart J 34: 2436-2443, 2013.

100. Grundy SM, Benjamin IJ, Burke GL, Chait A, Eckel RH, Howard BV, Mitch W, Smith SC Jr and Sowers JR: Diabetes and cardiovascular disease: A statement for healthcare professionals from the American Heart Association. Circulation 100: 1134-1146, 1999.

101. Schnell O, Cappuccio F, Genovese S, Standl E, Valensi P and Ceriello A: Type 1 diabetes and cardiovascular disease. Cardiovasc Diabetol 12: 156, 2013

102. Fioretto P, Dodson PM, Ziegler D and Rosenson RS: Residual microvascular risk in diabetes: Unmet needs and future directions. Nat Rev Endocrinol 6: 19-25, 2010.

103. Rosenberg DE, Jabbour SA and Goldstein BJ: Insulin resistance, diabetes and cardiovascular risk: Approaches to treatment. Diabetes Obes Metab 7: 642-653, 2005.

104. Li H, Horke S and Förstermann U: Vascular oxidative stress, nitric oxide and atherosclerosis. Atherosclerosis 237: 208-219, 2014.

105. Keul P, Sattler K and Levkau B: HDL and its sphingosine-1-phosphate content in cardioprotection. Heart Fail Rev 12: 301-306, 2007.

106. Karliner JS: Sphingosine kinase regulation and cardioprotection. Cardiovasc Res 82: 184-192, 2009. 
107. Karliner JS: Sphingosine kinase and sphingosine 1-phosphate in the heart: A decade of progress. Biochim Biophys Acta 1831: 203-212, 2013.

108. Whetzel AM, Bolick DT and Hedrick CC: Sphingosine-1-phosphate inhibits high glucose-mediated ERK1/2 action in endothelium through induction of MAP kinase phosphatase-3. Am J Physiol Cell Physiol 296: C339-C345, 2009.

109. Whetzel AM, Bolick DT, Srinivasan S, Macdonald TL, Morris MA, Ley K and Hedrick CC: Sphingosine-1 phosphate prevents monocyte/endothelial interactions in type 1 diabetic NOD mice through activation of the S1P1 receptor. Circ Res 99: 731-739, 2006.

110. Khafaji HA and Suwaidi JM: Atypical presentation of acute and chronic coronary artery disease in diabetics. World J Cardiol 6 : 802-813, 2014.

111. Jin ZQ, Karliner JS and Vessey DA: Ischaemic postconditioning protects isolated mouse hearts against ischaemia/reperfusion injury via sphingosine kinase isoform-1 activation. Cardiovasc Res 79: 134-140, 2008

112. Vessey DA, Kelley M, Li L and Huang Y: Sphingosine protects aging hearts from ischemia/reperfusion injury: Superiority to sphingosine 1-phosphate and ischemic pre- and post-conditioning. Oxid Med Cell Longev 2: 146-151, 2009.

113. Bonder CS, Sun WY, Matthews T, Cassano C, Li X, Ramshaw HS, Pitson SM, Lopez AF, Coates PT, Proia RL, et al: Sphingosine kinase regulates the rate of endothelial progenitor cell differentiation. Blood 113: 2108-2117, 2009.

114. Yu H, Yuan L, Xu M, Zhang Z and Duan H: Sphingosine kinase 1 improves cutaneous wound healing in diabetic rats. Injury 45: 1054-1058, 2014.

115. Furuya H, Wada M, Shimizu Y, Yamada PM, Hannun YA Obeid LM and Kawamori T: Effect of sphingosine kinase 1 inhibition on blood pressure. FASEB J 27: 656-664, 2013.

116.Igarashi $\mathrm{J}$ and Michel T: Sphingosine 1-phosphate and isoform-specific activation of phosphoinositide 3-kinase beta. Evidence for divergence and convergence of receptor-regulated endothelial nitric-oxide synthase signaling pathways. J Biol Chem 276: 36281-36288, 2001.

117. De Palma C, Meacci E, Perrotta C, Bruni P and Clementi E: Endothelial nitric oxide synthase activation by tumor necrosis factor alpha through neutral sphingomyelinase 2, sphingosine kinase 1, and sphingosine 1 phosphate receptors: A novel pathway relevant to the pathophysiology of endothelium. Arterioscler Thromb Vasc Biol 26: 99-105, 2006.

118. Yin Z, Fan L, Wei L, Gao H, Zhang R, Tao L, Cao F and Wang H: FTY720 protects cardiac microvessels of diabetes: A critical role of S1P1/3 in diabetic heart disease. PLoS One 7: e42900, 2012

119. Sukocheva O, Wadham C, Gamble J and Xia P: Sphingosine-1-phosphate receptor 1 transmits estrogens' effects in endothelial cells. Steroids 104: 237-245, 2015.
120. Margolis KL, Bonds DE, Rodabough RJ, Tinker L, Phillips LS, Allen C, Bassford T, Burke G, Torrens J and Howard BV; Women's Health Initiative Investigators: Effect of oestrogen plus progestin on the incidence of diabetes in postmenopausal women: Results from the Women's Health Initiative Hormone Trial. Diabetologia 47: 1175-1187, 2004.

121. Russo SB, Ross JS and Cowart LA: Sphingolipids in obesity, type 2 diabetes, and metabolic disease. Handb Exp Pharmacol 216: 373-401, 2013

122. Kontush A and Chapman MJ: Functionally defective high-density lipoprotein: A new therapeutic target at the crossroads of dyslipidemia, inflammation, and atherosclerosis. Pharmacol Rev 58: 342-374, 2006.

123. Barter PJ, Puranik R and Rye KA: New insights into the role of HDL as an anti-inflammatory agent in the prevention of cardiovascular disease. Curr Cardiol Rep 9: 493-498, 2007.

124. deGoma EM, deGoma RL and Rader DJ: Beyond high-density lipoprotein cholesterol levels evaluating high-density lipoprotein function as influenced by novel therapeutic approaches. J Am Coll Cardiol 51: 2199-2211, 2008.

125. Levkau B: HDL-S1P: Cardiovascular functions, disease-associated alterations, and therapeutic applications. Front Pharmacol 6: 243, 2015.

126. Tong X, Peng H, Liu D, Ji L, Niu C, Ren J, Pan B, Hu J, Zheng L and Huang Y: High-density lipoprotein of patients with type 2 diabetes mellitus upregulates cyclooxgenase-2 expression and prostacyclin I-2 release in endothelial cells: Relationship with HDL-associated sphingosine-1-phosphate. Cardiovasc Diabetol 12: 27, 2013.

127. Tong X, Lv P, Mathew AV, Liu D, Niu C, Wang Y, Ji L, Li J, Fu Z, Pan B, et al: The compensatory enrichment of sphingosine-1-phosphate harbored on glycated high-density lipoprotein restores endothelial protective function in type 2 diabetes mellitus. Cardiovasc Diabetol 13: 82, 2014.

128. Zhu D, Sreekumar PG, Hinton DR and Kannan R: Expression and regulation of enzymes in the ceramide metabolic pathway in human retinal pigment epithelial cells and their relevance to retinal degeneration. Vision Res 50: 643-651, 2010.

129. Mizugishi K, Yamashita T, Olivera A, Miller GF, Spiegel S and Proia RL: Essential role for sphingosine kinases in neural and vascular development. Mol Cell Biol 25: 11113-11121, 2005.

130. Tsuji T, Inoue M, Yoshida Y, Fujita T, Kaino Y and Kohno T: Therapeutic approach for type 1 diabetes mellitus using the novel immunomodulator FTY720 (fingolimod) in combination with once-daily injection of insulin glargine in non-obese diabetic mice. J Diabetes Investig 3: 132-137, 2012.

131. Gonzalez-Cabrera PJ, Brown S, Studer SM and Rosen H: S1P signaling: new therapies and opportunities. F1000Prime Rep 6 : 109, 2014. 